\title{
Performance of modified graphite as anode material for lithium-ion secondary battery
}

\author{
Hua Zheng ${ }^{1}$ and Myung-Soo Kim ${ }^{2, \$}$ \\ 'Department of Nano Science and Engineering, Myongji University, Yongin 449-728, Korea \\ ${ }^{2}$ Department of Chemical Engineering, Myongji University, Yongin 449-728, Korea
}

\author{
Article Info \\ Received 22 July 2011 \\ Accepted 26 October 2011 \\ *Corresponding Author \\ E-mail: myungkim@mju.ac.kr
}

\section{Open Access}

\section{DOI: http://carbonlett.org/} 10.5714/CL.2011.12.4.243

This is an Open Access article distributed under the terms of the Creative Commons Attribution Non-Commercial License (http://creativecommons.org/licenses/ by-nc/3.0/) which permits unrestricted non-commercial use, distribution, and reproduction in any medium, provided the original work is properly cited.

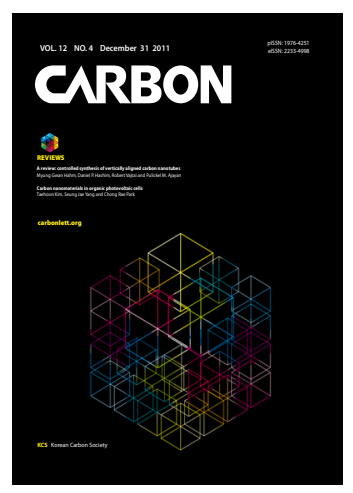

http://carbonlett.org

pISSN: 1976-4251

elSSN: 2233-4998

Copyright $\odot$ Korean Carbon Society

\begin{abstract}
Two different types of graphite, such as flake graphite (FG) and spherical graphite (SG), were used as anode materials for a lithium-ion secondary battery in order to investigate their electrochemical performance. The FG particles were prepared by pulverizing natural graphite with a planetary mill. The SG particles were treated by immersing them in acid solutions or mixing them with various carbon additives. With a longer milling time, the particle size of the FG decreased. Since smaller particles allow more exposure of the edge planes toward the electrolyte, it could be possible for the FG anodes with longer milling time to deliver high reversible capacity; however, their initial efficiency was found to have decreased. The initial efficiency of SG anodes with acid treatments was about $90 \%$, showing an over $20 \%$ higher value than that of FG anodes. With acid treatment, the discharge rate capability and the initial efficiency improved slightly. The electrochemical properties of the SG anodes improved slightly with carbon additives such as acetylene black (AB), Super P, Ketjen black, and carbon nanotubes. Furthermore, the cyclability was much improved due to the effect of the conductive bridge made by carbon additives such as AB and Super P.
\end{abstract}

Key words: flake graphite, spherical graphite, lithium-ion secondary battery, anode, carbon additive

\section{Introduction}

The exploitation of high-power secondary batteries has received considerable interest as part of efforts to solve environmental and energy problems while promoting social development. Lithium ion secondary batteries are one of the most important rechargeable batteries, and are widely used nowadays as power sources for portable electronic devices such as laptop computers, cellular phones and camcorders, due to their high energy density. Large size lithium ion batteries are also very attractive for use in hybrid electric vehicle or for fully electrical vehicle applications. The application requires high power, high energy density and a high efficiency power supply [1-3]. Studies on anode materials, aimed at improving material capacity and cyclability, have been active for many years [4-9].

The electrochemical properties of natural graphite anodes, involving initial efficiency, reversible capacity and cycle stability have been improved due to higher graphitization degree, higher purity, more suitable particle size distribution, and so on. Recently, natural graphite has come to be considered as a promising anode material for lithium ion batteries due to its high reversible capacity, appropriate charge/discharge profile and low cast. However, low first cycle efficiency and poor cycle stability have limited its practical use $[10,11]$.

Wang et al. [12] demonstrated that mechanical milling of natural graphite could be one possible way to produce disordered carbon atoms with large intercalation capacity. However, mechanically milled samples often have very large specific surface areas, leading to extensive irreversible reactions during the first charge. 
The treatment of graphite with oxidative solutions of $\mathrm{H}_{2} \mathrm{O}_{2}$, $\mathrm{Ce}\left(\mathrm{SO}_{4}\right)_{2}, \mathrm{HNO}_{3}$ and $\left(\mathrm{NH}_{4}\right)_{2} \mathrm{~S}_{2} \mathrm{O}_{8}$ resulted in marked improvement of its electrochemical performance as anode material for lithium ion batteries [13]. According to Wu et al. [13], the improvements might be due to the elimination of structural imperfections that have high levels of activity toward lithium, such as carbon chains, the introduction of more micropores/nano-channels, the modification of the surface of the graphite with a cover of a dense layer of oxides, and the improvement of the stability of the graphite structure.

Yang et al. [14] reported that the electron conductivity of multi-walled carbon nanotubes (MWCNTs) was around (1 4) $\times$ $10^{2} \mathrm{~S} / \mathrm{cm}$ along the nanotube axis and $5-25 \mathrm{~S} / \mathrm{cm}$ perpendicular to the axis. However, the conductivity of carbon black is around $2.1 \mathrm{~S} / \mathrm{cm}$. The electronic connections would be improved when MWCNTs are used instead of carbon black in the anode preparation. Li et al. [15] performed a comparative investigation of carbon black and MWCNTs as conducting additives, and had results that showed that the addition of MWCNTs remarkably increased the reversible capacity and cycling stability.

In this study, the objective is to improve the performance of graphite anodes by modifications such as optimum milling conditions, proper acid treatment, and introducing various carbon additives. In addition to a single treatment of acids or carbon additives for the graphite anodes, a mixture of different carbon additives was also applied. By changing the mixing ratio of carbon black and CNT, the obtained composite anode materials were tested to investigate the electrochemical characteristics.

\section{Experimental}

\subsection{Preparation and characterization of anode materials}

The flake graphite (FG, 10 15 $\mu \mathrm{m}$ of thickness, hundreds of $\mu \mathrm{m}$ of width) particles for the anode materials were prepared by pulverizing natural graphite with a planetary milled for $2 \sim 9 \mathrm{~h}$ and sieving it at 325 mesh. The spherical graphite (SG, $20 \mu \mathrm{m}$ of diameter) particles were treated with $10 \mathrm{wt} \%$ of $\mathrm{HNO}_{3}$ and $\mathrm{H}_{2} \mathrm{SO}_{4}$ for $2 \mathrm{~h}$. Acetylene black (AB, S. A. $60 \sim 80 \mathrm{~m}^{2} / \mathrm{g}$; Alfa Aesar, USA), conductive carbon black (Super P, TIMCAL, Switzerland), Ketjen black (KB) ethylene carbonate (EC, 600JD, S. A. $1270 \mathrm{~m}^{2} / \mathrm{g}$, P. H. Chemical) and CNT (diameter $10 \sim 15 \mathrm{~nm}$, Hanwha Nanotech, Korea) were introduced to SG particles by 1 $\mathrm{h}$ mixing with a magnetic stirrer. The contents of the additives in the SG anodes were varied in the range of $3 \sim 7 \mathrm{wt} \%$. The mixing ratios of the CNT to the conductive carbon black were varied, with the following values: $1: 4,2: 3$ and $1: 9$ at $5 \mathrm{wt} \%$ of total additive content.

\subsection{Half cell assembly}

The electrodes were prepared by mixing $93 \mathrm{wt} \%$ of the active anode materials and $7 \mathrm{wt} \%$ of polyvinylidene fluoride binder dissolved in 1-methyl-2-pyrrolidinone. The mixed slurry was then coated on copper foil by a Doctor Blade Method and dried at $80^{\circ} \mathrm{C}$ in a vacuum oven for $24 \mathrm{~h}$ before being compressed by a roll press at $80^{\circ} \mathrm{C}$. The prepared anodes in a $2.5 \times 2.5 \mathrm{~cm}$ size were kept in a glove box filled with argon. The prepared electrode was used as a working electrode and lithium foil adhered to a copper mesh with dimensions of $3.0 \times 3.0 \mathrm{~cm}$ was used as a counter electrode. $1 \mathrm{M} \mathrm{LiPE}_{6}$ salt dissolved in a mixture of EC, ethyl methyl carbonate, and dimethyl carbonate at 1:1:1 volume ratio was used as the electrolyte. The half cells were assembled in a glove box with an argon atmosphere using a polypropylene $\left(\right.$ Celgard $^{\circledR} 2400$ microporous membrane) separator to separate the cathode and the anode.

\subsection{Analysis of electrochemical properties}

The electrochemical properties of the half cells were estimated by using a WBCS-3000 Battery Charge/Discharge Cycler (Won A Tech Co., Korea) at a constant temperature of $25^{\circ} \mathrm{C}$. The charge characteristics were measured by applying the constant current $(\mathrm{CC})$ method at $0.2 \mathrm{C}$ for the first charge until reaching $0.005 \mathrm{~V}$ and then changing to the constant voltage method for the successive charge by reducing the current until $2.5 \%$ of the initial current was attained. For the discharge, the $\mathrm{CC}$ method was applied at $0.2 \mathrm{C}$ until reaching $2 \mathrm{~V}$. The current rates in the $\mathrm{CC}$ method increased to 1,5 and $10 \mathrm{C}$ for the high rate chargedischarge characteristics. $1 \mathrm{C}$ means a rate of current at which the full charge or discharge for the given anode sample would take $1 \mathrm{~h}$, assuming $300 \mathrm{mAh} / \mathrm{g}$ of capacity.

The microstructures of FG and SG were observed by a scanning electron microscope (SEM, 3500N, Hitachi Science System Ltd., Japan). The BET surface areas were measured by using an automatic surface area analyzer (Micromeritics, ASAP 2020).

\section{Results and Discussion}

\subsection{Natural FG as active anode materials for $\mathrm{Li}$ insertion}

Fig. 1 shows the SEM images of natural FG before and after milling with the planetary mill. It can be seen that the par-

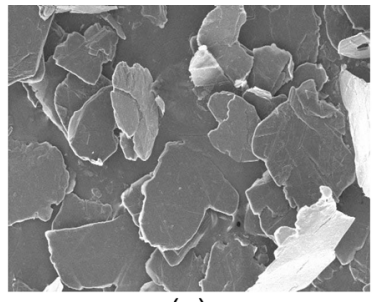

(a)

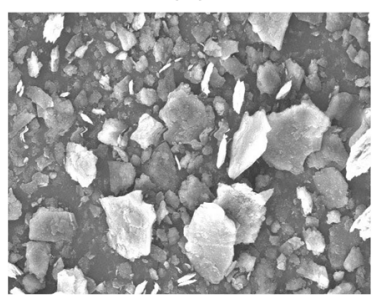

(c)

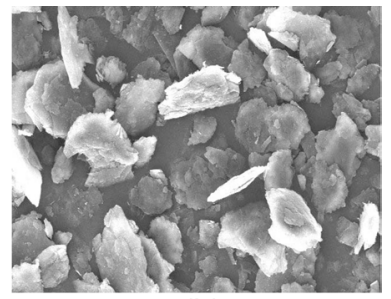

(b)

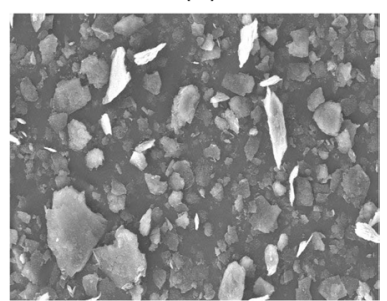

(d)
Fig. 1. Scanning electron microscope images of flake graphites: before milling (a), and after milling for $2 \mathrm{~h}(\mathrm{~b}), 5 \mathrm{~h}(\mathrm{c})$, and $9 \mathrm{~h}$ (d). 
Table 1. Discharge characteristics of flake graphite using different milling times

\begin{tabular}{ccccccc} 
Sample & $\begin{array}{c}\text { Reversible capacity } \\
(\mathrm{mAh} / \mathrm{g})\end{array}$ & $\begin{array}{c}\text { Initial efficiency } \\
(\%)\end{array}$ & \multicolumn{3}{c}{ Discharge rate capability (\%) } & \multicolumn{2}{c}{$\begin{array}{c}\text { Specific surface area } \\
\left(\mathrm{m}^{2} / \mathrm{g}\right)\end{array}$} \\
\cline { 5 - 6 } FG2.0h & 309 & 69.8 & 98.4 & 94.8 & 84.3 & 29.6 \\
\hline FG3.5h & 326 & 69.8 & 98.4 & 93.8 & 82.6 & 34.1 \\
\hline FG6.5h & 360 & 58.0 & 97.7 & 95.2 & 83.5 & 52.4 \\
\hline FG9.0h & 366 & 50.5 & 98.1 & 97.2 & 86.9 & 65.6 \\
\hline
\end{tabular}

FG: flake graphite.

Table 2. Performance of SG and SG treated with different acids or additives

\begin{tabular}{|c|c|c|c|c|c|}
\hline \multirow{2}{*}{ Sample } & \multirow{2}{*}{$\begin{array}{l}\text { Reversible capacity } \\
\qquad(\mathrm{mAh} / \mathrm{g})\end{array}$} & \multirow{2}{*}{ Initial efficiency (\%) } & \multicolumn{3}{|c|}{ Discharge rate capability (\%) } \\
\hline & & & $1 \mathrm{C}$ & $5 \mathrm{C}$ & $10 \mathrm{C}$ \\
\hline SG & 330 & 89.3 & 96.9 & 90.9 & 89.3 \\
\hline $\mathrm{SG}-\mathrm{HNO}_{3}$ & 351 & 91.8 & 98.6 & 96.6 & 90.7 \\
\hline $\mathrm{SG}-\mathrm{H}_{2} \mathrm{SO}_{4}$ & 333 & 90.6 & 98.7 & 97.1 & 91.9 \\
\hline SG-AB & 358 & 88.4 & 99.5 & 97.1 & 90.0 \\
\hline SG-Super P & 326 & 90.3 & 99.8 & 98.1 & 90.1 \\
\hline SG-KB & 315 & 75.0 & 98.9 & 97.0 & 81.5 \\
\hline SG-CNT & 316 & 80.7 & 99.8 & 96.2 & 88.5 \\
\hline SG-CNT-1 & 310 & 84.2 & 98.9 & 95.6 & 90.2 \\
\hline
\end{tabular}

SG: spherical graphite, AB: acetylene black, KB: Ketjen black, CNT: carbon nanotube.

ticle sizes of the FG became smaller with increased milling time. The milling treatment was able to cut the graphite particles into smaller pieces in directions both perpendicular and parallel to the basal planes [6]. Table 1 shows the discharge characteristics of the FG as a function of the milling time. It can be seen that the discharge capacity increased but that the initial efficiency decreased with the longer milling time. It can be conceived that a smaller particle size is favorable for high reversible capacity because of the larger exposure of the edge planes toward the electrolyte. As expected, the specific surface areas increased with the longer milling time, as shown in Table 1. However, the fine-particles of natural graphite will inevitably incur very large irreversible capacity due to the increased surface area, which will then decrease the coulombic efficiency [12].

\subsection{SG with a single treatment of acids or car- bon additives as active anode materials}

Table 2 shows the discharge characteristics of SG anodes using different acids and carbon additive treatments. The discharge capacity increased with the $\mathrm{HNO}_{3}$ treatment, and the discharge rate capability and the initial efficiency improved slightly with both acid treatments. These enhancements may be due to the elimination of structural imperfections, which results in high activity toward lithium ions.
It can be seen that the initial efficiency of SG did not change significantly with the AB or Super $\mathrm{P}$ additives but that it did decrease slightly with the CNT additive. The discharge rate capability of AB and Super P treated SG improved slightly as compared to that of SG. SG-CNT-1 indicates that CNT was treated with milling for $15 \mathrm{~min}$ before it was added to $\mathrm{SG}$. The milling treatment of the CNT improved the discharge rate capability and the initial efficiency of the CNT added SG anodes. This might indicate that the CNTs are significantly shortened and that they changed out of the entangled structure during the milling treatment. The shorted and disentangled CNTs help to increase the electrical conductivity within the composites of anode materials, causing them to exhibit better electrochemical performance.

Figs. 2 and 3 show the charge-discharge characteristics of the SG anodes treated with Super P and KB. The left curves present the charge property and the right curves present the discharge property. The discharge curves for Super P treated SG rise more in a more upright way in the range of $0.2 \sim 2 \mathrm{~V}$ and the discharge capacity was reduced more gradually with the increase of the C-rate up to $10 \mathrm{C}$, as compared to the case of the $\mathrm{KB}$ treated SG. As a result, the discharge capacity of the Super P treated SG at $10 \mathrm{C}$-rate was much higher than that of the $\mathrm{KB}$ treated $\mathrm{SG}$, although their discharge capacities at $0.2 \mathrm{C}$ were in the same range. The charge curve of $\mathrm{KB}$ treated $\mathrm{SG}$ was more extended than that of the Super P treated SG. This illustrates that the initial 


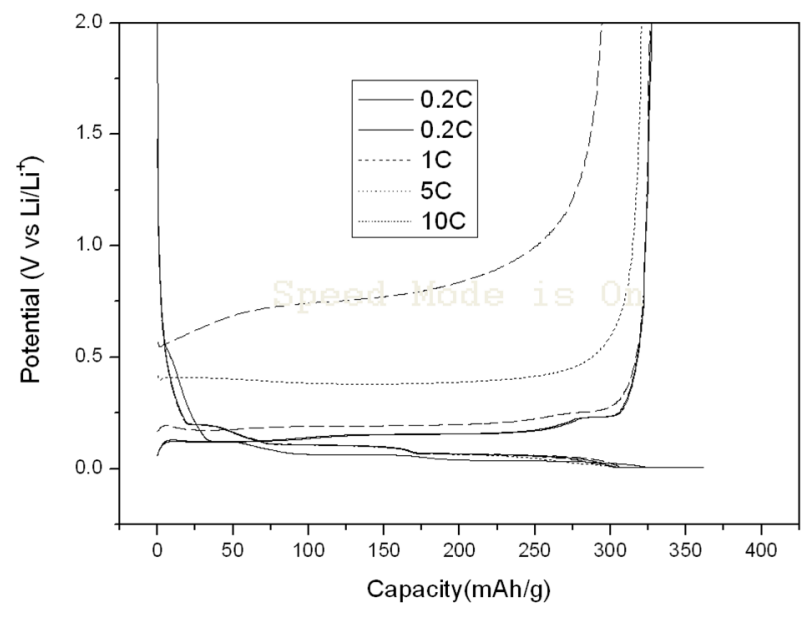

Fig. 2. Discharge characteristics of spherical graphite treated with Super $\mathrm{P}$.

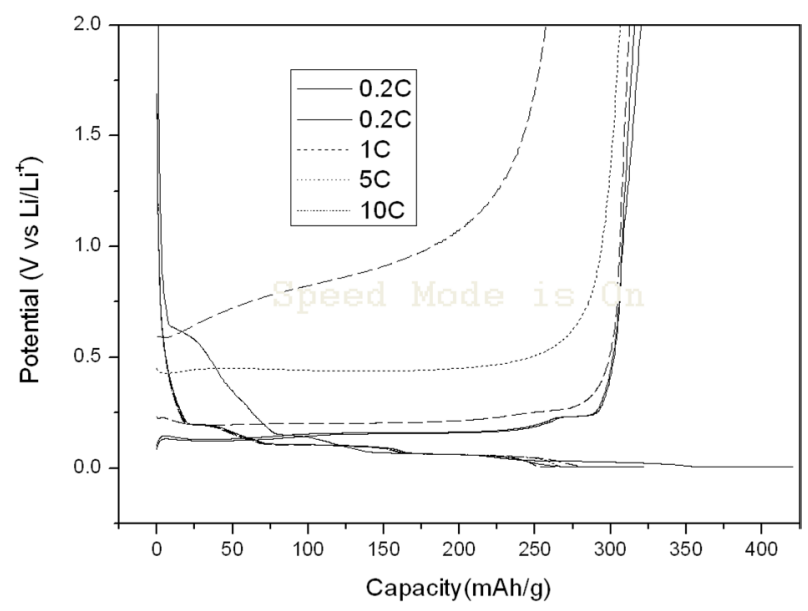

Fig. 3. Discharge characteristics of spherical graphite treated with Ketjen black.

efficiency of the KB treated SG is lower than that of the Super $P$ treated SG.

Fig. 4 presents the cyclic performance of the SG electrodes with different additives. The discharge capacity of SG anodes with the $\mathrm{AB}$ or Super $\mathrm{P}$ additives was retained even after 50 cycles but that of the SG anodes without the carbon additives dropped dramatically. The conductive additives might be concentrated near the contact points between the two adjacent graphite particles. Fig. 5 shows SEM images of the SG and the SG treated with different additives. It was confirmed that the additives were connected between the graphite particles, as shown in Figs. $5 \mathrm{~b}$ and c. These conductive bridges are very effective at improving the electrical contact between the graphite particles during the later cycles.

\subsection{SG anodes with different contents or a mixture of additives as active anode materials}

Table 3 shows the performance of SG anodes treated with different contents of Super P and with a mixture of CNT and Su-

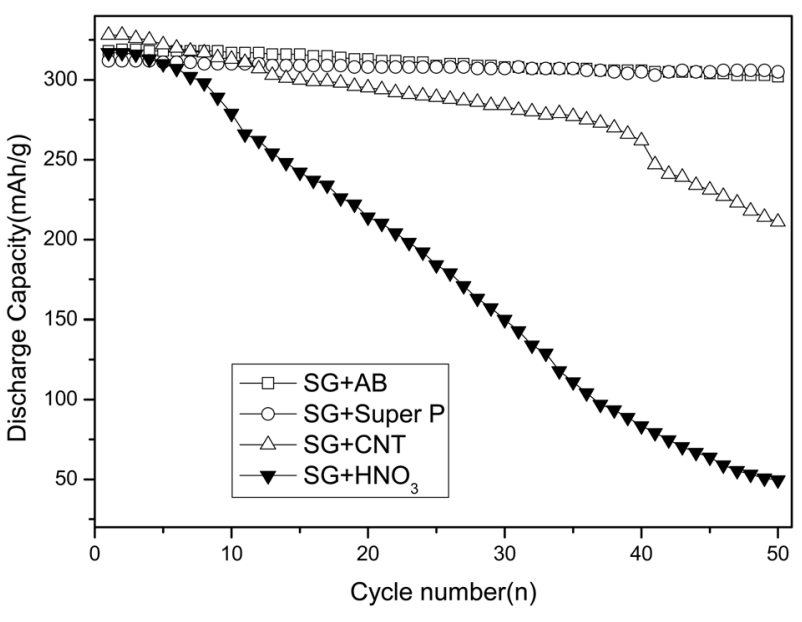

Fig. 4. Cyclic performances of spherical graphite electrodes treated with acid and different additives.

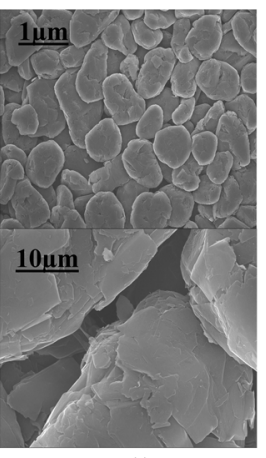

(a)

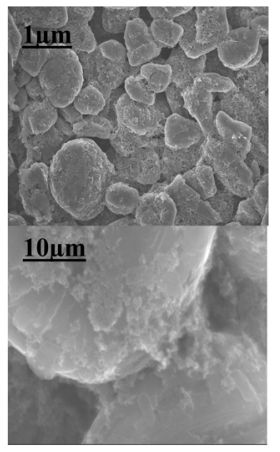

(b)

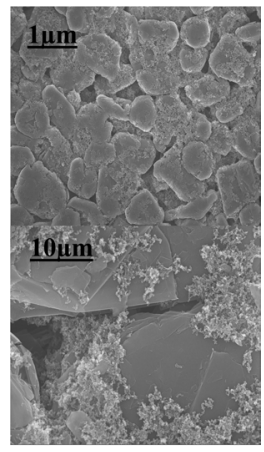

(c)
Fig. 5. Scanning electron microscope images of spherical graphite (SG) (a), SG treated with acetylene black (b), and SG treated with Super P (c).

per P. The reversible capacity of the SG anodes did not change significantly with the variation of Super P content. However, the discharge rate capability improved with an increase of the Super $P$ content and the initial efficiency showed the highest performance at 5 wt of Super P content.

The SG anodes treated with a mixture of CNT and Super P had a relatively high reversible capacity as compared to those treated with a single additive. The reversible capability showed the highest value of $381 \mathrm{mAh} / \mathrm{g}$ at a 1:4 ratio of CNT to Super P. However, the SG anodes treated with a mixture of CNT and Super P showed a lower initial efficiency and discharge rate capability than those treated with a single additive. The SG anodes treated with a CNT and $\mathrm{AB}$ mixture showed a relatively high 10 C-rate capability of $91.7 \%$.

\section{Conclusions}

In order to improve the performance of anode materials for lithium ion secondary batteries, milling treatment for FG, and either acid or carbon additive treatments for SG, were carried out. With the increased milling time, the discharge capacity of the FG increased but the initial efficiency decreased. The 
Table 3. Performance of SG treated with different contents or mixture of additives

\begin{tabular}{|c|c|c|c|c|c|}
\hline \multirow{2}{*}{ Sample } & \multirow{2}{*}{$\begin{array}{l}\text { Reversible capacity } \\
\qquad(\mathrm{mAh} / \mathrm{g})\end{array}$} & \multirow{2}{*}{ Initial efficiency (\%) } & \multicolumn{3}{|c|}{ Discharge rate capability (\%) } \\
\hline & & & $1 \mathrm{C}$ & $5 \mathrm{C}$ & $10 \mathrm{C}$ \\
\hline SG-Super $\mathrm{P}_{3 \%}$ & 342 & 86.7 & 98.1 & 94.2 & 89.4 \\
\hline SG- Super $\mathrm{P}_{5 \%}$ & 326 & 90.3 & 99.8 & 98.1 & 90.1 \\
\hline SG- Super $\mathrm{P}_{7 \%}$ & 335 & 84.4 & 98.3 & 95.9 & 92.7 \\
\hline CNT-Super P 1:9 & 365 & 84.5 & 99.0 & 93.7 & 87.7 \\
\hline CNT-Super P 1:4 & 381 & 85.4 & 99.5 & 97.1 & 88.3 \\
\hline CNT-Super P 2:3 & 352 & 83.6 & 98.7 & 94.7 & 87.1 \\
\hline CNT-AB & 301 & 83.3 & 99.9 & 96.0 & 91.7 \\
\hline
\end{tabular}

SG: spherical graphite, CNT: carbon nanotube, AB: acetylene black.

$\mathrm{HNO}_{3}$ and $\mathrm{H}_{2} \mathrm{SO}_{4}$ treated SG showed a slightly higher reversible capacity, a higher discharge rate capability, and higher initial efficiency than the SG without any treatment due to the elimination of structural defects of graphite by the acid treatment. The Super P treated SG also showed a slightly improved initial efficiency and discharge rate capability as compared to that of the SG without any treatment. The SG anodes treated with a mixture of CNT and Super P had a relatively high reversible capacity as compared to that of anodes treated with a single additive. The SG anodes treated with a mixture of $\mathrm{CNT}$ and $\mathrm{AB}$ showed a higher $10 \mathrm{C}$-rate discharge capability than those treated with a single additive. With treatment with carbon black additives such as AB or Super P, the discharge capacity was retained even after 50 cycles. The conductive additives and binder might become concentrated near the contact points between the two adjacent graphite spheres and these conductive bridges will be very effective for improving cyclability.

\section{Acknowledgements}

This work was supported by Basic Science Research Program through the National Research Foundation of Korea (NRF) funded by the Ministry of Education, Science and Technology (MEST) (2010-0025033).

\section{References}

[1] Vasilchina H, Aleksandrova A, Momchilov A, Banov B, Predoana L, Barau A, Zaharesku M. Spherical graphite as anode in high efficient lithium batteries. Proceedings of the International Workshop "Portable and Emergency Energy Sources--from Materials to Systems", Primorsko, Bulgaria (2005).

[2] Zhang Y, Zhang XG, Zhang HL, Zhao ZG, Li F, Liu C, Cheng HM. Composite anode material of silicon/graphite/carbon nanotubes for Li-ion batteries. Electrochim Acta, 51, 4994 (2006). http://dx.doi. org/10.1016/j.electacta.2006.01.043.

[3] Li X, Yoon SH, Du K, Zhang Y, Huang J, Kang F. An urchin-like graphite-based anode material for lithium ion batteries. Electro- chim Acta, 55, 5519 (2010). http://dx.doi.org/10.1016/j.electacta.2010.04.101.

[4] Wu YS, Wang YH, Lee YH. Performance enhancement of spherical natural graphite by phenol resin in lithium ion batteries. J Alloys Compd, 426, 218 (2006). http://dx.doi.org/10.1016/j.jallcom.2005.11.093.

[5] Zhao H, Ren J, He X, Li J, Jiang C, Wan C. Modification of natural graphite for lithium ion batteries. Solid State Sci, 10, 612 (2008). http://dx.doi.org/10.1016/j.solidstatesciences.2007.10.017.

[6] Wang X, Gai GS, Yang YF, Shen WC. Preparation of natural microcrystalline graphite with high sphericity and narrow size distribution. Powder Technol, 181, 51 (2008). http://dx.doi.org/10.1016/j. powtec.2007.06.025.

[7] Wu HC, Guo ZZ, Wen HP, Yang MH. Study the fading mechanism of LiMn2O4 battery with spherical and flake type graphite as anode materials. J Power Sources, 146, 736 (2005). http://dx.doi. org/10.1016/j.jpowsour.2005.03.070.

[8] Guoping W, Bolan Z, Min Y, Xiaoluo X, Meizheng Q, Zuolong Y. A modified graphite anode with high initial efficiency and excellent cycle life expectation. Solid State Ionics, 176, 905 (2005). http:// dx.doi.org/10.1016/j.ssi.2004.11.009.

[9] Yoshio M, Wang H, Fukuda K, Umeno T, Abe T, Ogumi Z. Improvement of natural graphite as a lithium-ion battery anode material, from raw flake to carbon-coated sphere. J Mater Chem, 14, 1754 (2004). http://dx.doi.org/10.1039/b316702j.

[10] Zou L, Kang F, Zheng YP, Shen W. Modified natural flake graphite with high cycle performance as anode material in lithium ion batteries. Electrochim Acta, 54, 3930 (2009). http://dx.doi. org/10.1016/j.electacta.2009.02.012.

[11] Wang H, Umeno T, Mizuma K, Yoshio M. Highly conductive bridges between graphite spheres to improve the cycle performance of a graphite anode in lithium-ion batteries. J Power Sources, 175, 886 (2008). http://dx.doi.org/10.1016/j.jpowsour.2007.09.103.

[12] Wang H, Ikeda T, Fukuda K, Yoshio M. Effect of milling on the electrochemical performance of natural graphite as an anode material for lithium-ion battery. J Power Sources, 83, 141 (1999). http:// dx.doi.org/10.1016/S0378-7753(99)00288-8.

[13] Wu YP, Jiang C, Wan C, Holze R. Effects of pretreatment of natural graphite by oxidative solutions on its electrochemical performance as anode material. Electrochim Acta, 48, 867 (2003). http://dx.doi. org/10.1016/s0013-4686(02)00780-6. 
[14] Yang DJ, Wang SG, Zhang Q, Sellin PJ, Chen G. Thermal and electrical transport in multi-walled carbon nanotubes. Phys Lett A, 329, 207 (2004). http://dx.doi.org/10.1016/j.physleta.2004.05.070.

[15] Li XL, Du K, Huang JM, Kang FY, Shen WC. Effect of carbon nanotubes on the anode performance of natural graphite for lithium ion batteries. J Phys Chem Solids, 71, 457 (2010). http://dx.doi. org/10.1016/j.jpcs.2009.12.010. 